\title{
A Case of Complication of Bronchial Asthma and Rheumatoid Arthritis both of which Healed Completely after Repeated Intradermal Injections with a Non-Specific Antigen Preparation
}

\author{
Kimihiko Okazaki* \\ Okazaki Medical Clinic, Ukyoku Kyoto Japan
}

*Corresponding Author: Kimihiko Okazaki, Okazaki Medical Clinic, Ukyoku Kyoto Japan, Email: ma13081x@ma1.seikyou.ne.jp

\begin{abstract}
Mutual exchanges between specific and non-specific antibody molecules on receptors on the surface of immune cells should take place after an accumulation of non-specific antibodies in the patients' bodies. These exchanges will bring about decompositions of combinations of immune cells and specific antibodies. These decompositions equal eliminations of causes of immune diseases.
\end{abstract}

According to the traditional concept of the contemporary Immunology, neither autoimmune diseases nor allergic diseases can be cured completely. Nevertheless, a fortunate coincidence led the author to discover a novel concept that eliminations of the causes of these diseases are possible. In other words, combinations of pathogenic antibodies with responsible cells, namely, cytolytic $\mathrm{T}$ lymphocytes in cases of autoimmune diseases and mast cells in cases of allergic diseases, can be decomposed by replacing the pathogenic antibodies with non-specific antibodies. In more detail, intradermal injections with a non-specific antigen preparation induce productions of nonspecific antibodies in the body of the patient. Repetitions of the injections bring about an accumulation of them. Accumulated non-specific antibodies will occupy most of the receptors on the surface of responsible cells. When the accumulation reaches the sufficient level, virtually no pathogenic antibodies would remain on the receptors. That is, no causes of the diseases remain.

To work out the above mentioned concept, it is necessary to have the patients make non-specific antibodies for themselves. In order for the patients to do so, they need to receive intradermal injections with nonspecific antigen preparations. Consequently, non-specific antibodies accumulate in the patients' bodies, which may replace specific antibodies from respective cells bringing about elimination of causes of the diseases. Needless to mention, where there is no cause, there is no disease. Details are demonstrated elsewhere [1]. The conceptual basis of antibodies' mutual exchange is existence of equilibrium state among antibody molecules in the vicinity of receptors, which was first proposed by Porter [2]. One of the contemporary trends concerning treatments of allergic diseases is an intravenous infusion of solution of nonspecific antibody preparation. However, a large number of these infusions are dangerous because anti-antibody antibody might be produced in the recipient's body, which may cause an anaphylactic reaction.

\section{Case1}

A 55-year-old woman(A.T.) visited the author's clinic on November 9, 2012. She claimed that she had had a bronchial asthma since the fall of 2004 and that she often suffers from attacks when the weather is bad. She started receiving intradermal injections with $0.1 \mathrm{ml}$ of 10,000 fold with saline diluted Neurotropin, a product of Nippon Zohki Pharmaceutical Company(Osaka), consisting of an extract of rabbit skin inflamed by inoculation of Vaccinia virus, at 2 15 day intervals on November 9, 2012. In the spring of 2014, she was free from asthma-attack even when a typhoon was approaching. In the beginning of October, 2015, she claimed morning stiffness of the first joints of her both 5th toes. She kept receiving the same injection. Two months later, she claimed additional morning stiffness and pain at the first joint of her left finger. She kept receiving the same injection. 
A Case of Complication of Bronchial Asthma and Rheumatoid Arthritis both of which Healed Completely after Repeated Intradermal Injections with a Non-Specific Antigen Preparation

One month later, she said that her morning stiffness and pain had been restricted to immediately after getting up every morning and that she felt weak pains on both sides of both feet when weight was given. After additional four similar injections, she became free from any symptoms concerning joints. The total number of the injections was 227. The total time-duration was 4 years, 11 months, and 5 days.

\section{REFERENCES}

[1] Okazaki, K., (2009): Therapeutic Significance of Non-Specific Antigens As Anti-Allergic and Anti-Autoimmune Agents. Pharmacometrics, 76, 105-107.

[2] Porter, R.R. (1959): The hydrolysis of rabbit gamma-globulin and antibodies by crystalline papain. Biochem. J. vol. 73: 119.

Citation: Kimihiko Okazaki. A Case of Complication of Bronchial Asthma and Rheumatoid Arthritis both of which Healed Completely after Repeated Intradermal Injections with a Non-Specific Antigen Preparation. ARC Journal of Clinical Case Reports. 2018; 4(1): 6-7. doi:dx.doi.org/ 10.20431/2455-9806.0401002.

Copyright: () 2018 Authors. This is an open-access article distributed under the terms of the Creative Commons Attribution License, which permits unrestricted use, distribution, and reproduction in any medium, provided the original author and source are credited. 